\title{
Phrenic Vein
}

National Cancer Institute

\section{Source}

National Cancer Institute. Phrenic Vein. NCI Thesaurus. Code C53062.

The veins that run parallel to the phrenic arteries which include the two superior and two inferior phrenic veins. 